\title{
How YOU CAN REASONABLY Form EXPECTATIONS WHEN YOU'RE EXPECTING
}

\author{
Nathaniel Sharadin
}

\begin{abstract}
L. A. Paul has argued that an ordinary, natural way of making a decision-by reflecting on the phenomenal character of the experiences one will have as a result of that decision-cannot yield rational decision in certain cases. Paul's argument turns on the (in principle) epistemically inaccessible phenomenal character of certain experiences. In this paper I argue that, even granting Paul a range of assumptions, her argument doesn't work to establish its conclusion. This is because, as I argue, the phenomenal character of an experience supervenes on epistemically accessible facts about its non-phenomenal character plus what the deciding agent is like. Because there are principles that link the non-phenomenal character of experiences (together with what a particular agent is like) to the phenomenal character of experiences, agents can reasonably form expectations about the valence of the phenomenal character of the experiences that they are deciding whether to undergo. These reasonable expectations are, I argue, enough to make the ordinary, natural way of making a decision yield rational decision.
\end{abstract}

\section{Introduction}

Sometimes, when we are trying to make a choice, we reflect on the phenomenal character of the possible outcomes of our choice. That is, we reflect on "what things would be like" if we chose one way or another. This is a natural way of deciding what to do. In this journal, L. A. Paul (2015) has argued that this natural approach to decision is inapt for a range of choices where the phenomenal character of the outcomes of our choices is inaccessible to us. In particular, Paul argues that this way of deciding cannot yield a rational choice when it comes to deciding whether or not 
to have a child. This argument has been picked up widely by the popular press. ${ }^{1}$ I think it is mistaken.

Paul's argument turns on the (in principle) epistemically inaccessible phenomenal character of certain experiences. Here I argue that, even granting Paul a range of assumptions, her argument doesn't work to establish its conclusion. This is because, as I will argue, the phenomenal character of an experience supervenes on its non-phenomenal character plus what the deciding agent is like. Hence, because agents can and often do have epistemic access to these facts, and because there are principles that link the non-phenomenal character of experiences (together with what a particular agent is like) to the phenomenal character of experiences, agents can reasonably form expectations about the valence of the phenomenal character of the experiences that they are deciding whether to undergo. And these reasonable expectations about whether the phenomenal character of an experience will be positive or negative are, I argue, enough to make the ordinary, natural way of making a decision yield rational decision. My focus throughout will be, as in Paul's argument, on the decision to procreate. In the conclusion I'll briefly explain how my argument can be extended to other similar decisions. Before all that, Paul's argument.

\section{Paul's Argument}

According to Paul, reflecting on what it would be like to have a child cannot rationally yield either the decision to have a child or the decision to remain childless. This is because, according to Paul, the phenomenal character of the outcome where you have a child is unavailable to you: you cannot know what it is like to have a child, and so your choice cannot be rationally grounded in considerations of what it would be like. Having a child is, in her words, "epistemically transformative": information about what it is like to have a child is in principle unavailable to childless adults; in order to have an epistemic grip on the phenomenal character of having a child, you must therefore actually have one $(2015,8-9)$. Of course, what this means is that prospective parents cannot rationally appeal to considerations concerning what it would be like to have a child in order to decide whether to have one, since they do not-and cannot-know what, in fact, it would be like. Paul explains $(2015,11)$ :

The trouble comes from the fact that, because having one's first child is epistemically transformative, one cannot determine the value of what it's like to have one's own child before actually having her. This means that the subjective unpredictability attending the act of having one's first child makes the story about family planning into little more than

\footnotetext{
${ }^{1}$ Gopnik (2013); Burkeman (2013a,b); Rothman (2013); Lombrozo (2013a,b); Marshall (2013); Moran (2013); Bartlett (2013).
} 
pleasant fiction. Because you cannot know the value of the relevant outcome, there is no rationally acceptable value you can assign to it. The problem is not that a prospective parent can only grasp the approximate values of the outcomes of her act, for then, at least, she might have some hope of meeting our norms for ordinary decision-making. The problem is that she cannot determine the values with any degree of accuracy at all.

You might object: the distinctive and, let's grant, epistemically inaccessible, phenomenal character of the outcome of having one's own child is just one feature of that outcome. There are other features of the outcome of having one's own child that prospective parents can know about. Some of these are phenomenal but not distinctive to having one's own child, and some are not phenomenal at all. For instance, prospective parents can know that having a child will be expensive. This would be a nonphenomenal feature of the outcome. They can also know that having a child will affect their sleep patterns in certain predictable ways. This is a phenomenal feature of the outcome of having one's own child, but it is one that even prospective parents can be phenomenally acquainted with; after all, they can have the relevant experience by agreeing to watch someone else's newborn, or by setting alarms to go off at random intervals throughout the night. These are just two examples: there are other nonphenomenal and phenomenal features of the outcome of having one's own child that prospective parents can know about. Here, then, is the worry: Can't prospective parents rationally decide whether to have a child on the basis of reflecting on what it would be like to have a child in terms of these epistemically accessible (phenomenal and nonphenomenal) features of what it is like to have one?

Paul anticipates this objection. Her reply is that the distinctive phenomenal character of the outcome of having a child - the one that is epistemically inaccessible to prospective parents-is likely to swamp all other considerations in determining whether it is rational to have a child. That is, she grants that there might be nondistinctive phenomenal or nonphenomenal features of the outcome of having one's own child that are epistemically accessible by prospective parents. But, she claims, these features of the outcome of having one's own child will likely be swamped by the distinctive phenomenal character of the outcome: as she says, "even if other [features of the] outcomes are relevant, the value of the phenomenal outcome, when it occurs, might be so positive or so negative that none of the values of the other relevant outcomes matter" $(2015,17)$. Paul's idea is plausible: what really matters, when it comes to determining whether it is rational to have a child, is not whether you will lose sleep (and what that feels like), nor whether it will be expensive (and what it's like have less disposable income), but instead what it's distintictively like to have a child. Deciding to have a child isn't simply a matter of deciding whether to get less sleep or 
be less prodigal: After all, you might know everything about the physical and fiscal cost of children and still wonder whether or not it makes sense to have a child. So the distinctive phenomenal character of the outcome of having a child plausibly swamps other considerations when it comes to deciding whether to have a child.

Here Paul's comparison with ordering food from an unfamiliar menu is helpful. If someone else is paying for your meal, then we can suppose that the only thing that matters is what the food tastes like. What it is like to taste the food, as we might put it, swamps all the other considerations. Unfortunately, this puts you in in an unenviable situation. This is because, since you do not know what it's like to taste the items on the menu, there seems to be nothing that could rationally ground your decision for one item over another. You could flip a coin. But then you wouldn't be deciding based on considerations having to do with what it will be like to taste the food you'll thereby have ordered. And so your choice would be disanalogous to the decision to have a child based on considerations having to do with what it will be like to actually have one. Indeed, it would be like deciding whether to have a child by flipping a coin. So if all that matters is what the food tastes like, and you, ex hypothesi, have no idea what that is like, then it seems you're rationally at a loss. So it goes with children: if what really matters is the distinctive phenomenal character of what it is like to have a child, and you have no idea what that is like, then it seems you're rationally at a loss.

\section{Linking Principles and Rational Expectation}

Let's grant that the distinctive phenomenal character of the outcome of having a child always swamps all other considerations when it comes to whether it is rational to decide to have a child. As Paul points out, there are two ways this might happen: swamping can happen in either direction $(2015,17)$. Either the distinctive phenomenal character of having a child of one's own might be such that, whatever negative nondistinctive phenomenal and nonphenomenal features of the outcome of having one's own child, the "what it is like" to have a child of one's own makes the net value of the outcome of having one's own child positive. Intuitively, this is what happens when the loss in sleep and financial hardship of having a child of one's own are outweighed by the distinctive phenomenal character of the experience. Or the distinctive phenomenal character of having a child of one's own might be such that, no matter what positive nondistinctive phenomenal and nonphenomenal features of the outcome of having one's own child there might be, the "what it is like" to have a child of one's own makes the net value of the outcome of having a child negative. Either way, swamping is a matter of the distinctive phenomenal character of having a child of one's own being the final arbiter of whether the overall value of having one's own child is positive or negative. If the distinctive phenomenal character is one 
way, that value will be positive; if it is another, it will be negative. In order to capture this idea, I'll say that the distinctive phenomenal character of having one's own child is valenced: it is either positive or negative. Let's also grant that the distintinctive phenomenal character of the outcome of having one's own child is in principle epistemically inaccessible to prospective parents. That is, there is no way for prospective parents to know the content of the phenomenological experience of "what it is like" to have a child of their own before they in fact do. Does it follow from these two assumptions that prospective parents cannot rationally decide whether to have a child by reflecting on what it would be like to have one? It does not.

For notice that, if the distinctive phenomenal character is the final arbiter of whether the net value of the outcome of having one's own child is positive or negative, then in order to know whether it is rational to have a child prospective parents do not need to know the content of that phenomenal character, and they do not need to be assign any particular value to that experience: they only need to know its valence-whether it is positive or negative. And that, I claim, is something prospective parents can know-or at least, something about which they can form reasonable expectations. Let me explain.

A new experience that is the same in respect of its non-phenomenal character can strike two individuals differently in terms of its phenomenal character. This is because the phenomenal character of a new experience will be shaped not just by features of the experience itself but also by features of the individual undergoing it. And where two individuals differ in the relevant features, the same experience will, in terms of its phenomenology, be correspondingly different. For example, borrowing from Paul (who in turn borrows from David Lewis [1990]), we can imagine two individuals, $A$ and $B$, tasting Vegemite for the first time. Now, Vegemite has certain non-phenomenal, physical characteristics that contribute to what the experience of tasting it is like. Nonetheless, what A's experience of tasting it is like might differ widely from what $B$ 's experience of tasting it is like: $A$ might find it pleasantly savory and salty, whereas $B$ might find it overwhelmingly heady. And this difference in the character of $A$ and $B$ 's phenomenology of tasting Vegemite for the first time will not be due to a difference in the Vegemite tasted. It will be due, instead, to a difference in some relevant features of $A$ and $B$. Perhaps $A$ likes strongly flavored things, and $B$ doesn't. In fact, we can go further than this. We can say that the particular phenomenal character of a new experience for an agent always supervenes on two things:

(1) The non-phenomenal character of the experience.

(2) What the agent is like.

Call this claim, the claim that the phenomenal character of an experience for an agent depends both on what the experience is like, non-phenomenally 
speaking, and what the agent is like, Phenomenal Supervenience. Phenomenal Supervenience isn't a controversial claim: it simply says that what it is like to have an experience will depend both on features of that experience and on features of the agent undergoing the experience. How does this bear on Paul's argument?

Notice first there are facts that can take us from knowledge of (1) and (2) in a particular case to a prediction about the valence of the phenomenal character of the relevant experience in that case. ${ }^{2}$ For instance, we know what Vegemite is non-phenomenally like and so know what the non-phenomenal character of the experience of tasting Vegemite is like. Suppose in addition to knowing what Vegemite is like I know that $B$, who is about to taste Vegemite for the first time, is a "supertaster." (A supertaster is someone who, probably due at least in part to genetic factors, has a significantly increased number and sensitivity of tastebuds. Such people are much less likely to enjoy strongly flavored foods such as Vegemite (Prescott et al. 2001). Given this knowledge of what Vegemite is like (it is very salty) and what $B$ is like (she is a supertaster), we can safely predict-though not, of course, with certainty-that $B$ 's experience of tasting Vegemite for the first time will be negatively valenced. This is not to say that we can predict what the content of $B$ 's phenomenal experience will be like. Nor is it to say that we can assign a particular value to that experience. It is to say that we can rationally predict that $B$ will not enjoy the experience-we can predict that the experience will, overall, be negatively valenced. And, importantly, $B$ can predict this fact too, so long as she knows the relevant facts about Vegemite and herself. Such statistical facts are what I will call linking principles: they link knowledge of (1) and (2) to predictions of the valence of the phenomenal character of an experience.

Of course, Paul isn't concerned to argue that we can't rationally decide to try Vegemite for the first time. But the example is illustrative. Despite the fact that prior to trying Vegemite for the first time $B$ cannot know what it is like to taste Vegemite, $B$ can safely predict that she will not like it-she can predict that, all things considered, it will be a negatively valenced phenomenal experience for her. This is because of the existence of a principle supported by empirical facts about the connection between what she is like and what the phenomenal character of her experience will be like, given what the non-phenomenal character of that experience is like. What the example illustrates is that that Paul's argument turns on denying the existence of any such linking principles in the case of having a child. There are two problems with denying the existence of such linking principles.

The first problem is that denying the existence of such principles seems to commit us to the claim that the experience of having a child is not just epistemically transformative, but also personally so. To see this, notice

\footnotetext{
${ }^{2}$ For a similar idea, see Dougherty et al. 2015, 307.
} 
that in the absence of personal transformation there must in every case be, as a matter of simple causal necessity, some principle linking what a particular experience is like non-phenomenally and what an agent is like to how that experience will affect them. We could deny that this was so in any particular case of an experience if we thought that part of the experience's effect on a person was to transform them into someone different. Then the effect that an experience had on any particular individual could not be "read off" what the experience is like together with what the agent is like, for what the agent is like would depend on how the experience affected them. This would amount to a rejection of Phenomenal Supervenience in a particular case. But this way of denying the existence of linking principles is unavailable to Paul. This is because Paul explicitly denies that having a child is always personally transformative $(2015$, fn. 21$)$.

Of course, it is open to Paul to argue that, although having a child is not always personally transformative, it often is; that is, that the probability that having a child will be personally transformative is high. Indeed, she seems to suggest this: "[T] he claim that having a child is epistemically transformative does not entail that it is also personally transformative: for most people, it is. For some people, it isn't" (2015, fn. 21, emphasis added). It might appear that, if true, this idea would rescue Paul's argument. After all, if prospective parents can reasonably expect themselves to be personally (and not just epistemically) transformed by an experience, then principles linking the non-phenomenal character of an experience with what they are like right now won't be any help at all. And so Paul's conclusion would appear to follow: prospective parents couldn't rationally decide in the ordinary, natural way. But there are two reasons why this appearance is misleading: the idea that parenthood is often-or, as we'll see, even always-personally transformative won't save the argument. ${ }^{3}$

First, if the probability that parenthood will be personally transformative is less than one, then in any particular case it makes sense to ask: What is the probability that this case of parenthood will be personally transformative for this agent? Whether an experience is or is not likely to be personally transformative is not a random affair. The deliberate decision to order catfish rather than trout is not likely to transform me into a different person. But it might: it might, for instance, if I thought of myself (prior to ordering the catfish) as someone who strictly adhered to traditional Jewish dietary laws forbidding the consumption of fish without scales. The decision to abandon these laws has a good chance of making me into a "different person" in the relevant sense. What this case illustrates is that whether or not a decision (and the experience that is its natural upshot) is likely to be personally transformative can itself be something about which we form reasonable expectations. You can see where this is going. We can form reasonable expectations about whether an experience will in fact be

\footnotetext{
${ }^{3}$ Thanks to an anonymous referee for pressing me to be clearer on this point.
} 
personally transformative by thinking about what sort of person an agent is right now, and how experiences of the relevant sort affect people like that (i.e., whether these experiences are likely to be personally transformative for that sort of agent). ${ }^{4}$

The situation is even worse than it appears. Even if you think, implausibly in my view, that we can never safely predict whether some experience will be personally transformative, we have been given no reason to think that there are no further linking principles that tell us how an agent is likely to be personally transformed by an experience. That is, we have not been given any reason to deny the existence of principles that say how an agent that is thus-and-so right now is likely to be after the agent undergoes some experience. And we have positive reason for thinking there are such principles, for the same reasons we have for thinking there are the first sort of linking principles. How an agent is (likely to be) transformed by an experience supervenes on how the agent is right now and what the experience is like. Selfish cads do not become selfless altruists by adopting puppies, though they may become less selfish. Personal transformation may be commonplace, but Damascene conversion is not. So, even if we grant that we can't have any reasonable expectations regarding whether an experience will be personally transformative for an agent, we can form reasonable expectations about how an agent is likely to be transformed by it. And then we're back to the races: with these expectations in hand we can form expectations about the valence of the phenomenal character of the experience not for the agent as she is now, but for the agent as she is likely to be afterward. ${ }^{5}$

I said there were two problems with denying the existence of principles linking the non-phenomenal character of having a child with the valence of the phenomenal experience thereof. The first problem, as we just saw, was that denying the existence of such principles seems to commit one either to the (implausible) claim that having a child is always personally transformative, or to the (equally implausible) claim that we can't reasonably form expectations about whether some experience will be personally transformative or how it will be so. The second problem is that there

\footnotetext{
${ }^{4}$ After all, that's why it sometimes makes sense to say to some of the people you know that, say, reading a particular book will change their life, and why it never makes sense to say such a thing to every person you know.

${ }^{5}$ At the very least, this narrows the scope of Paul's argument to those decisions where two conditions are met: (i) it is plausible that there is a high (or certain) probability in this particular case that the decision will be personally transformative; and (ii) there is no way to reasonably form expectations about how an agent will be transformed. It might well be that the decision to procreate is sometimes like this for some people, but I seriously doubt that that the decision to procreate in general is like this. And while decisions other than prospective parenthood might also sometimes be like this for some people, I only somewhat more tentatively doubt whether there any interesting decisions to which Paul's argument is meant to apply (one's choice of career, one's choice of spouse) that are like this in general. (Thanks to an anonymous referee for suggesting this point.)
} 
manifestly are such linking principles, and we know what some of them are. For just one example, depression on the part of either parent, but especially maternal depression, is linked to both affective and behavioral disorders on the part of children (Lovejoy et al. 2000; Tan and Ray 2005). ${ }^{6}$ And parents of affectively or behaviorally disordered children report significantly higher rates of stress and lower levels of subjective well-being-as good a measure as any of the valence of the phenomenal character of their experience of what it is like to have a child (Tan and Ray 2005, 77). What this means is that if we know (1) what it is non-phenomenally like to have a child and (2) that some agent is depressed (or socioeconomically disadvantaged, see fn. 5), then we have at least some reason to expect that the phenomenal character of the experience of having a child will, for that agent, be negatively valenced. Of course, that reason to believe the phenomenal character of the experience of having a child will be negatively valenced might not be decisive. There might be further reasons to expect the experience will be negative that contribute to our expectation-or, indeed, there might be countervailing reasons, grounded in other linking principles, to expect that it will be positive. The point is just that such expectations are sometimes warranted. They are warranted on the grounds that, given knowledge of the non-phenomenal features of an experience and knowledge of what some particular agent is like, we can justifiably believe facts about how that experience is likely to phenomenally affect the agent. This is true in the case of the experience of having a child no less than it's true in the case of trying Vegemite for the first time. This should come as no surprise at all: what people are like helps determine how things turn out for them. And, thanks to years of pyscho- and sociological research, we can often safely predict how things will turn out for an agent given enough psycho- or sociological information about them.

Of course, the situation is no different when it comes to ourselves than it is in the case of others. Or at least, it is not relevantly different. Just as I can know that, given that some agent is depressed, the phenomenal character of her experience of having a child is unlikely to be positive, I can know of myself that, given I am depressed, the phenomenal character is unlikely to be positive. And so, ceteris paribus, I can safely predict that it would be unwise, just now at least, for me to have that experience.

Here is another way to put the same point. In the course of her argument, Paul claims that agents deciding whether to procreate cannot use reports of the phenomenal character of similar experiences garnered from other agents because those reports will not be able to impart the distinctive phenomenal character of the relevant experience. That's how having children for the first time is like tasting Vegemite for the first time-you can't know what it's like just from hearing about it from evangelical Australians. And

\footnotetext{
${ }^{6}$ Similar findings have (perhaps unsurprisingly, and probably relatedly) connected persistent poverty and overall socioeconomic disadvantage with cognitive, affective, and behaviorial disorders on the part of children. See McLoyd 1998.
} 
since that distinctive phenomenal character is what matters to making the decision in a rational way, prospective parents can't rationally decide whether to have children of their own. In effect, what I've just argued is that, even granting that agents deciding whether to procreate can't access the distinctive phenomenal character of having a child of their own, they can form reasonable expectations about the valence of that experience given the existence of empirical principles that link the sort of people they are now to the sort of phenomenal experiences they are likely to have if they have a child of their own.

\section{Concluding Remarks}

The upshot of the argument, then, is this: Paul is quite correct to highlight the epistemically transformative nature of the experience of having a child. Prospective parents cannot know what it is phenomenally like to have a child of their own before they do so, just as prospective diners cannot know what it is like to taste Vegemite before they do. As Paul points out, this means that prospective parents cannot rationally decide to have a child by reflecting on the phenomenal character of that experience: it's in principle epistemically inaccessible to them. But this does not mean that prospective parents cannot rationally decide to have a child by reflecting on what it is like to have a child. It just means they have to take a somewhat circuitous route: prospective parents must reflect on the non-phenomenal features of the experience, on what they themselves are like, and on the principles that link how they are to how the experience is likely to affect them. By doing so, prospective parents can form rational expectations about how the experience of having a child is likely to phenomenally affect them, and so can form rational expectations about the phenomenal valence of that experience. This means that, given Paul's assumption (which, here at least, I grant) that the phenomenal character of the experience is really the final arbiter of whether or not it is rational to decide to have a child, prospective parents can rationally decide whether or not to procreate.

Although Paul's argument focuses on the decision to procreate, it is not limited to that decision. If correct, Paul's argument might apply equally well to the decision to change careers, start a new hobby, engage in a new romantic relationship, or become interested in a new cuisine. What my argument shows is that Paul's argument doesn't work in the case of the decision to have a child because we think there are linking principles that can help us form reasonable expectations about how experiences will phenomenally affect us. But, I think, the same goes for these other areas of decision: they too have linking principles. For example, if you know what philately is non-phenomenally like, and you know pretty well what you are like, then you can form reasonable expectations about how the distinctive phenomenology of philately (if there is one) is likely to strike you. (I, for one, am pretty sure I would not like it.) 
Let me close by highlighting two features of the view I've defended here. First, it can still be useful for agents to reflect directly (i.e., not via linking principles) on what they think some new experience will be like. This is because when a childless agent reflects on what it would be like to have a child, even if this reflection is epistemically unreliable, it sometimes has a certain valence-the agent might experience the reflection itself as overall positive, overall negative, or somehow mixed. And even if this reflection has little to do with what in fact it will be like for the agent to have a child of their own (that's the hinge on which Paul's argument tries to turn), it can still have important evidential value. This is because it helps reveal the antecedent attitude the agent has toward the experience. And the antecedent attitude an agent has toward an experience is part of who she is - and that, as we already know, will affect how the experience will strike her. And so reflecting on what a new experience might be like can still play a role in rationally deciding whether to undergo that experience. Not because it can provide good information about what the experience will actually be like, but because it can provide good information about what we ourselves are like. ${ }^{7}$

Second, note that the account I've given here of how it can be rational to decide under conditions of uncertainty about the phenomenal character of a new experience (e.g., having a child of one's own) by reflecting on what it is like to do so squares very nicely with our practice of giving and asking for advice when deliberating about whether to take the plunge. For instance, when we want to know whether it is rational for us to have a child, we not only ask people who have had children what it is like, we ask people who we think are a lot like ourselves in relevant respects (e.g., people with comparable socioeconomic status or similar values). ${ }^{8}$ This is presumably because we think that the way the experience affects others is a good guide to how it will affect us: we think there are principles that link the way people are (not just socioeconomically, but also in terms of their values, commitments, cares, and so on) with how experiences affect them. And so we can use others' experiences to guide rational expectations about the value - or at least the valence-of the phenomenal character of the experience we are deliberating about whether to have.

Nathaniel Sharadin E-mail :sharadin@unc.edu

\section{References:}

Bartlett, Tom. 2013. "Maybe You Should Have a Baby.” The Chronicle of Higher Education. http://chronicle.com/blogs/percolator/maybe-you-should-have-a-baby/32379.

\footnotetext{
${ }^{7}$ I'm grateful to an anonymous referee for this point.

${ }^{8}$ Compare Harman 2015, 328.
}

Acknowledgements Thanks to Finnur Dellsén, Megan Mitchell, Kate Nolfi, Wesley Sauret, and two anonymous referees for their helpful feedback. 
Burkeman, Oliver. 2013a. "This Column Will Change Your Life: Transformative Experiences." The Guardian. http://www.theguardian.com/lifeandstyle/2013/apr/06/ this-column-change-life-transformative-experiences.

Burkeman, Oliver. 2013b. "We're Truly in the dark when it comes to life's most important decisions.” Business Insider. http://www.businessinsider.com/the-problem-with-advice-2013-4.

Dougherty, Tom, Sophie Horwitz, and Paulina Sliwa. 2015. "Expecting the Unexpected.” Res Philosophica 92 (2): 301-321. http://dx.doi.org/10.11612/resphil.2015.92.2.5.

Gopnik, Alison. 2013. "Is It Possible to Reason About Having a Child?" The Wall Street Journal. http://online.wsj.com/news/articles/ SB10001424127887324432404579052901271445142.

Harman, Elizabeth. 2015. "Transformative Experience and Reliance on Moral Testimony." Res Philosophica 92 (2): 323-339. http://dx.doi.org/10.11612/resphil.2015.92.2.8.

Lewis, David. 1990. "What Experience Teaches.” In Mind and Cognition: A Reader, edited by William Lycan, 499-519. Oxford: Blackwell.

Lombrozo, Tania. 2013a. "Is Having a Child a Rational Decision?” NPR. http://www.npr. org/blogs/13.7/2013/03/11/173977133/is-having-a-child-a-rational-decision.

Lombrozo, Tania. 2013b. "Is it Rational to Have a Child? Can Psychology Tell Us?" Psychology Today. http://www.psychologytoday.com/blog/explananda/201303/ is-it-rational-have-child-can-psychology-tell-us.

Lovejoy, M. Christine, Patricia A. Graczyk, Elizabeth O'Hare, and George Neuman. 2000. "Maternal Depression and Parenting Behavior: A Meta-analytic Review." Clinical Psychology Review 20 (5): 561-592. http://dx.doi.org/10.1016/S0272-7358(98)00100-7.

Marshall, Richard. 2013. "Metaphysical (Interview with L.A. Paul).” 3:AM Magazine. http://www.3ammagazine.com/3am/metaphysical/.

McLoyd, Vonnie C. 1998. "Socioeconomic disadvantage and child development." American Psychologist 53 (2): 185-204. http://dx.doi.org/10.1037/0003-066X.53.2.185.

Moran, Collete. 2013. "The Decision Whether to Have Children Cannot Be Made Rationally." The National Review. http://www.nationalreview.com/home-front/358115/ decision-whether-have-children-cannot-be-made-rationally-colette-moran.

Paul, L. A. 2015. "What You Can't Expect When You're Expecting.” Res Philosophica 92 (2): 149-170. http://dx.doi.org/10.11612/resphil.2015.92.2.1.

Prescott, John, Nini Ripandelli, and Ian Wakeling. 2001. "Binary Taste Mixture Interactions in PROP Non-tasters, Medium-tasters and Super-tasters." Chemical Senses 26 (8): 993-1003. http://dx.doi.org/10.1093/chemse/26.8.993.

Rothman, Joshua. 2013. “The Impossible Decision.” The New Yorker. http://www.newyorker. com/books/page-turner/the-impossible-decision.

Tan, Susan and Joseph Ray. 2005. "Depression in the young, parental depression and parenting stress." Australasian Psychiatry 13 (1): 76-79. http://dx.doi.org/10.1080/j. 1440-1665.2004.02155.x. 